\title{
MENINGKATKAN KONSEP DIRI AKADEMIK SISWA DENGAN TEKNIK MIRACLE QUESTION PADA SISWA KELAS VIII DI SMP NEGERI 2 SUMBERREJO
}

\author{
Susilawati \\ SMP Negeri 2 Sumberrejo \\ fadila.bjn@gmail.com
}

\section{ABSTRACT}

One of the elements forming student self-identity in the academic field is the academic selfconcept. Some cases of students whose learning outcomes have not been achieved or there is no understanding in certain lessons is due to not understanding their own academic selfconcept. Counseling Guidance in Schools as a forum for providing services to students is indispensable in providing counseling services. One of the services provided is group counseling. The techniques provided in group counseling services in this study are the myeracle question technique, through this technique students will collaborate with the counselor in group counseling services in finding solutions so that they can make changes to individuals so that they can promote a positive academic self-concept. This study aims to improve students' academic self-concept and use classroom action research with 2 cycles, namely cycles 1 and 2 . The results of changes in cycles 1 and 2 are an increase of $10 \%$ towards the very high category, and $7 \%$ of the subjects into the high category.

\section{ABSTRAK}

One of the elements forming student self-identity in the academic field is the academic selfconcept. Some cases of students whose learning outcomes have not been achieved or there is no understanding in certain lessons are due to not understanding their own academic selfconcept. Counseling Guidance in Schools as a forum for providing services to students is

\section{Kata Kunci:} indispensable in providing counseling services. One of the services provided is group counseling. The techniques provided in group counseling services in this study are the miracle question technique, through this technique students will collaborate with the counselor in group counseling services in finding solutions so that they can make changes to individuals so that they can promote a positive academic self-concept. This study aims to improve students' academic self-concept and use classroom action research with 2 cycles, namely cycles 1 and 2 . The results of changes in cycles 1 and 2 are an increase of $10 \%$ towards the very high category and $7 \%$ of the subjects into the high category.

Cara mengutip: Susilawati, S. (2020). Meningkatkan Konsep Diri Akademik Siswa Dengan Teknik Miracle Question Pada Siswa Kelas VIII Di SMP Negeri 2 Sumberrejo . Nusantara of Research : Jurnal Hasil-Hasil Penelitian Universitas Nusantara PGRI Kediri (e-Journal), 7(1), 30-36. https://doi.org/10.29407/nor.v7i1.15054

\section{PENDAHULUAN}

Siswa-siswi SMP Negeri 2 Sumberrejo Bojonegoro terletak dikawasan pedesaan. Sebagian besar siswa yang mendaftar adalah dari penduduk sekitar. Meskipun didaerah pedesaan akan tetapi murid di SMP Negeri 2 sumberrejo juga lumayan banyak. SMP yang ada dikecamatan Sumberrejo mulai tahun ini mengalami persaingan dalam jumlah murid karena adanya zona. Pendaftaran masuk karena zona membuat anak mengalami kekecewaan 
karena tidak bisa masuk sekolah sesuai yang diimpikan. Beberapa anak yang nilainya bagus dan mendapat prestasi ingin memilih sekolah yang lebih bagus menurut dia, akan tetapi karena terkena dampak zona dia akhirnya harus mendaftar di SMP Negeri 2 Sumberrejo, dan itu sangat mempengaruhi konsep diri akademik siswa tersebut, sehingga mempengaruhi kepercayaan diri dalam hal akademik. Data tentang konsep diri akademik diperoleh setelah disebarkan angket kepada peserta didik yang didalamnya terdapat siswa diterima karena pengaruh zona dan ditemukan beberapa konsep dirinya yang rendah. Remaja adalah masa dimana mulainya untuk menetapkan ego identitas pada dirinya, namun banyak remaja yang mengalami krisis identitas pada dirinya. Krisis identitas terjadi kepada remaja karena konsep diri pada remaja masih dalam keadaan yang labil,terkadang posistif dan terkadang menjadi negatif (Gunanto, Sutoyo, dan Rahman, 2013 : 19). Sehingga, hal tersebut membuat para remaja mengalami krisis antara identitas dan kebingungan identitas dirinya (Erikson dalam Feist dan Feist, 2013:303). Konsep diri akademik yang positif akan mendorong siswa menjadi optimal pada masa belajarnya. Menurut Shevelson dan Bolus, sebagaimana dikutip oleh Saifullah (2015:251) siswa yang memeliki konsep diri positif memiliki konsep positif untuk mampu melakukan penerimaan diri, kepercayaan diri, dan penghargaan diri yang berkaitan dengan bidang akademik yang digeluti di sekolah.

Konsep diri akademik merupakan tugas perkembangan yang harus dipenuhi oleh individu pada masa belajarnya. Teknik miracle question bisa menjadi alternatif untuk dilaksanakan pada seting sekolah debagai wadah pengembangan konsep diri akademik siswa karena pada seting pendidikan akan lebih efektif dengan adanya suatu terapi yang digunakan dalam waktu yang singkat juga adanya kolabolasi dengan berbagai pihak yang terkait. Miracle question adalah teknik yang digunakan konselor untuk membantu klien dalam menetapkan visi ke depan. De Jong dan Berg (dalam Gerald Corey, 2002:8) mengenali sejumlah alasan bahwa pertanyaan ajaib adalah suatu teknik yang bermanfaat. Dengan bertanya kepada klien untuk mempertimbangkan bahwa suatu keajaiban akan terjadi membuka luasnya kemungkinankemungkinan di masa depan. Klien didorong untuk bebas bermimpi sebagai cara mengenali perubahan yang memang mereka inginkan. Pertanyaan ini memiliki focus masa depan yang dari situ klien bisa dapat memulai mempertimbangkan suatu jenis kehidupan yang berbeda yang tidak didominasi oleh suatu masalah tertentu. Intervensi ini mengalihkan penekanan keduanya yaitu masalah masa lalu maupun masa sekarang terhadap hidup di masa yang akan datang

Marsh (2003) menyatakan bahwa konsep diri akademis dapat membuat individu menjadi lebih percaya diri dan merasa yakin akan kemampuan mereka karena sebenarnya konsep diri akademis itu sendiri mencakup bagai mana, individu bersikap, merasa, dan mengevaluasi kemampuannya.Oleh sebab itu, konsep diri akademik menjadi tugas perkembangan yang wajib dilalui atau diselesaikan dengan baik oleh setiap siswa.

Konsep diri akademik merupakan bagian dari konsep diri. Menurut Lent, Brown, \& Gore, sebagaimana dikutip oleh Cokley (2000:149) konsep- diri akademik didefinisikan sebagai sikap, perasaan dan persepsi relatif terhadap satu adalah keterampilan intelektual atau akademik. Diperkuat oleh Dagnew (2015:216) Konsep diri akademik didefinisikan sebagai 
bagaimana seseorang merasakkan tentang dirinya sendiri dalam sekolah atau seting akademik, atau dalam kaitannya dengan kemajuan akademis siswa.

Konsep diri akademik merupakan tugas perkembangan yang harus dipenuhi oleh individu pada masa belajarnya.Teknik miracle question bisa menjadi alternatif untuk dilaksanakan pada setting sekolah debagai wadah pengembangan konsep diri akademik siswa karena pada seting pendidikan akan lebih efektif dengan adanya suatu terapi yang digunakan dalam waktu yang singkat juga adanya kolabolasi dengan berbagai pihak yang terkait. Menurut penelitian dari Franklin, Moore, \& Hopson (2008:26) menyatakan intervensi untuk dilakuan di sekolah sebaik dengan jangka waktu yang pendek dan memuat suatu perubahan. Intervensi untuk mendukung gagasan tersebut yaitu dengan menggunakan teknik miracle question. De Jong dan Berg (dalam Gerald Corey, 2002:8) mengenali sejumlah alasan bahwa pertanyaan ajaib adalah suatu teknik yang bermanfaat. Dengan bertanya kepada klien untuk mempertimbangkan bahwa suatu keajaiban akan terjadi membuka luasnya kemungkinankemungkinan di masa depan. Klien didorong untuk bebas bermimpi sebagai cara mengenali perubahan yang memang mereka inginkan. Maka demikian pada penelitian ini bertujuan untuk memberikan pemahaman kepada pembaca untuk segera meningkatkan konsep diri akademik siswa dengan menggunakan teknik Miracle Question secara efektif.

\section{METODE}

Penelitian Tindakan Bimbingan Konseling ini dilaksanakan di kelas VIII-D di SMP Negeri 2 Sumberrejo. Subyek dalam penelitian ini adalah Siswa kelas VIII-D, kemudian diberi skala konsep diri akademik dan yang hasilnya rendah diadakan konseling kelompok. Dalam pengambilan sampel peneliti menggunakan teknik purposive sampling dengan jumlah 5 dari 30 anak yang mengalami konsep diri akademik masih rendah di kelas tersebut. Dalam penyebaran angket ini peneliti menggunakan skala konsep diri akademik yang sudah diuji reliabilitas dan validitasnya dalam skripsi Hana Nida Khafiya (2018).

Adapun tahapan dari penelitian tindakan kelas dalam artikelnya Akhmad Sudrajat (2008), tahapan yang digunakan adalah: 1) Perencanaan, dalam hal ini dijabarkan dalam bentuk perencanaan (rencana) guru BK sebelum melakukan suatu tindakan. Rencana ini meliputi menetapkan tujauan yang akan dicapai dalam proses kegiatan layanan, menentukan metode yang akan dilakukan dalam melakukan layanan dengan teknik Miracle Question, dan Menyiapkan media atau instrumen yang diperlukan dalam kegiatan layanan; 2) Implementasi Tindakan, Merupakan pelaksanaan tindakan yang dilakukan untuk meningkatkan konsep diri akademik siswa melalui layanan konseling dengan teknik Miracle Question. Hal yang dilakukan dalam tahap ini antara lain menjalin kebersamaan dan saling memahami, melakukan kolaborasi antara konselor dan konseli untuk menemukan solusi, memberikan umpan balik atas apa yang mereka lakukan setelah mereka memahami konsep diri akademik; 3) Observasi dan Interpretasi, pada bagian ini merupakan observasi dari tindakan atau layanan yang sudah 
dilakukan konselor terhadap pengaruh yang diperoleh dari hasil / tindakan yang sudah diimplementasikan; 4) Analisis dan Refleksi, setelah melakukan observasi maka dilakukan analisa. Analisa merupakan kegiatan untuk menganalisis atau mencermati hasil dari layanan atau tindakan dalam PTBK ini. Analisis digunakan untuk mengetahui bagaimana hasil dari layanan atau tindakan yang sudah dilakukan. Melaksanakan peninjauan ulang untuk menuju kesempurnaan teknik layanan konseling berikutnya. Refleksi dilakukan dengan cara menilai semua proses yang ada pada penelitian tindakan ini sudah berhasil atau belum. Hasil dari analisis akan menjadi dasar refleksi. Refleksi digunakan untuk mengecek apa yang menjadi kekurangan atau kelebihan dari layanan atau tindakan. Apabila hasil dari analisis mengungkapkan butuh siklius 2 karena hasil belum maksimal maka direfleksi akan muncul hal-hal apa saja yang sekiranya membutuhkan perbaikan pada siklus 2 .

HASIL

Siswa yang diterima di SMP Negeri 2 Sumberrejo sebagian besar karena pengaruh aturan zona. Sebagian besar siswa yang mendaftar adalah dari penduduk sekitar. Meskipun didaerah pedesaan akan tetapi murid di SMP Negeri 2 sumberrejo juga lumayan banyak. SMP yang ada dikecamatan Sumberrejo mulai tahun ini mengalami persaingan dalam jumlah murid karena adanya zona. Pendaftaran masuk karena zona membuat anak mengalami kekecewaan karena tidak bisa masuk sekolah sesuai yang diimpikan. Beberapa anak yang nilainya bagus dan mendapat prestasi ingin memilih sekolah yang lebih bagus menurut dia, akan tetapi karena terkena dampak zona dia akhirnya harus mendaftar di SMP Negeri 2 Sumberrejo, dan itu sangat mempengaruhi konsep diri akademik siswa tersebut.

Data dalam penelitian ini diperoleh dari siswa kelas VIII-D SMP Negeri 2 Sumberrejo 2020/2021 yang berjumlah 30 siswa yang telah diberikan angket konsep diri akademik. Angket konsep diri akademik yang sudah diuji dibagikan kepada siswa kelas VIII-D, kemudian dari hasil tersebut dilihat pada siswa yang konsep dirinya masih tergolong rendah.Siswa yang tergolong rendah ditemukan 5 siswa. Data yang diperoleh dalam penelitian ini digunakan untuk mengetahui tingkat konsep diri akademik siswa dan kemudian diberikan layanan pada siklus 1.

Dari fenomena tersebut, peneliti memberikan layanan dengan konseling kelompok dengan membahas masalah konsep diri akademik. Dari skala psikologis konsep diri akademik yang disebarkan diperoleh data ada sekitar 30\% ( 5 dari 30) siswa yang memiliki konsep diri akademik dengan kategori rendah, 17\% (9 dari 30) siswa memeiliki konsep diri akademik sedang dan 30\% (16 dari 30 ) siswa memiliki konsep diri tinggi.dan 53\%(16 dari 30) siswa yang memiliki konsep diri sangat tinggi. Sedangkan siswa memiliki $0 \%$ dari 30 siswa.

Hasil penelitian dari observasi sejak siklus 1 hingga siklus 2 digambarkan dalam gambar 1 sebagai berikut: 


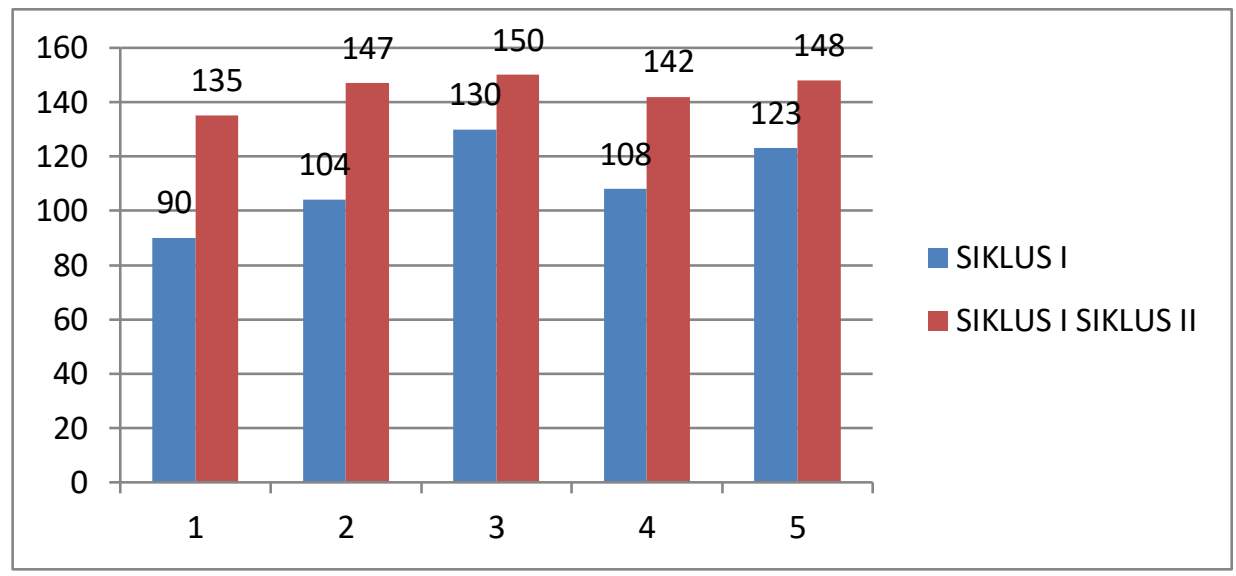

Gambar 1. Grafik Penelitian Siklus I dan Siklus II

Dari grafik di atas bisa dijelaskan bahwa indikator konsep diri akademik meningkat dari subyek nomer 1 sampai subyek nomer 5 masing-masing mengalami peningkatan pada kegiatan siklus 2. Teknik miracle question diharapkan mampu meningkatkan konsep diri akademik siswa, hal tersebut terlihat dan terangkum dalam tabel dibawan ini:

Tabel 1. Komparasi Kategori Konsep Diri Akademik Prasiklus, Siklus I dan Siklus 2

\begin{tabular}{clccc}
\hline NILAI & KATEGORI & Pra Siklus & SIKLUS I & SIKLUS II \\
\hline $147-152$ & Sangat Tinggi & 0 & 0 & 3 \\
$111-146$ & Tinggi & 0 & 2 & 2 \\
$75-110$ & Sedang & 0 & 3 & 0 \\
$38-74$ & Rendah & 5 & 0 & 0 \\
Jumlah & & 5 & 5 & 5 \\
\hline
\end{tabular}

Dari tabel ini menunjukkan bahwa subyek penelitian secara individu bergerak progresif, pada kondisi awal seluruh subyek memiliki kategori Konsep Diri Akademik yang rendah. Tindakan pada siklus 1 telah mampu membawa perubahan komposisi ada 3 subyek yang mampu meningkat menuju kategori sedang, dan 2 subyek ke kategori tinggi.Tindakan pada siklus 2 mampu meningkatkan 3 subyek pada kategori sangat tinggi dan 2 subyek dalam kategori tinggi.

\section{PEMBAHASAN}

Pada penelitian ini, penulis membagi distribusi skor konsep kiri akademik dalam 4 kategori yaitu tingkat konsep diri akademik rendah, sedang, tinggi dan sangat tinggi. Dari skala psikologis yang di sebarkan pada pra penelitian diperoleh data ada sekitar 17\% (5 dari 30) siswa yang memiliki konsep diri akademik yang rendah. Dan 30 \% (9 dari 30) siswa memiliki konsep diri akademik sedang. 53\% (16 dari 30) siswa konsep diri akademiknya ting gi dan 0\% siswa kategori sangat tinggi. Dalam hal ini yang peneliti tetapkan sebagai subyek penelitian adalah berjumlah 5 orang, dengan pertimbangan agar kelompok yang dibentuk lebih efisien meskipun dalam konseling kelompok boleh lebih sebagaimana persyaratan jumlah anggota konseling kelompok. Sebenarnya peneliti bisa menggabungkan rendah dan sedang dalam 
layanan konseling kelompok, tetapi lebih difokuskan pada subyek khusus kategori rendah. Selain itu juga karena dalam penelitian ini adalah di masa pandemi sehingga peneliti mengambil subyek yang jumlahnya relatif sedikit agar lebih efisien. Setelah itu peneliti melakukan tahap siklus 1 dengan perubahan pada tahap kategori sedang dan tinggi, yaitu dari 17\% (5 dari 30) siswa menjadi $0 \%$ menuju kategori sedang 10\% (3 dari 30) siswa dan 7\% (2 dari 30 ) siswa ke kategori tinggi. Dalam siklus 1 berarti ada peningkatan ke kategori sedang dan tinggi sejumlah 17\%.Akhirnya peneliti melakukan siklus 2 bertujuan untuk lebih menguatkan konsep diri akademik siswa dan mengalami kenaikan dari kategori sedang dan tinggi menjadi tinggi dan sangat tinggi, yaitu 2 subyek kearah kategori tinggi dan yang 3 subyek menjadi sangat tinggi.

Dari hasil observasi peneliti 5 siswa yang mempunyai Konsep Diri Akademik rendah rendah menunjukkan lebih banyak menunjukkan gejala kurang mampu dalam memahami mata pelajaran, malu bertanya ketika pelajaran berlangsung, merasa patah semangat sekolah dan tidak baik dalam hal apapun di sekolah sehingga kadang-kadang siswa juga lebih cenderung mengabaikan tugas sekolah yang dikarenakan siswa tersebut belum mampu menerima dirinya sendiri apa adanya.Hal ini sejalan dengan Cookley, (2007) mengutarakan dimana konsep diri juga berhubungan dengan perasaan terkait sikap dari kemampuan akademik atau intelektual siswa seperti halnya membandingkan kemampuan diri dengan kemampuan siswa atau teman lain.

Teknik Miracle question menitikkan pada menciptakan kesadaran. Menciptakan kesadaran merupakan bagian dari ketika siswa menemukan solusi dari permasalhannya. Teknik ini mendorong untuk mengetahui tujuan konseling yang diinginkan oleh konseli. Seperti" Bagaimana perasaanmu jika di sekolah SMP yang kamu tempati kamu menjadi kebanggan satu sekolah?" sehingga konseli mengetahui tujuan dan menemukan solusi untuk meningkatkan konsep diri akademiknya dengan melakukan recana tindakan.

\section{KESIMPULAN DAN SARAN}

Dari skala psikologis konsep diri akademik rendah. Dan $30 \%$ (9 dari 30) siswa memiliki konsep diri akademik sedang. 53\% (16 dari 30) siswa konsep diri akademiknya tinggi dan $0 \%$ siswa kategori sangat tinggi. Subyek penelitian adalah berjumlah 5 orang, dengan alasan 5 subyek tersebut tergolong subyek dengan konsep diri yang masih rendah. Dalam penelitian ini mulai dari siklus 1 dari 17\% (5 dari 30 ) siswa yang rendah konsep dirinya berubah menjadi $0 \%$ subyek dengan kategori konsep diri akademik rendah menjadi kategori sedang dan tinggi. Itu berarti dalam penelitian ini bisa menurunkan sejumlah $17 \%$ konsep diri yang rendah ke arah Konsep diri yang sedang dan tinggi. Sedangkan dalam siklus 2 ada 3 subyek naik ke kategori sangat tinggi. Hal tersebut menunjukkan ada peningkatan 10\% ke arah kategori sangat tinggi, dan 7\% subyek menjadi kategori tinggi.

Teknik Miracle Question adalah teknik bertanya yang digunakan konselor untuk membantu konseli bagaimana menetapkan visi ke depan, Dengan bertanya kepada klien untuk mempertimbangkan bahwa suatu keajaiban akan terjadi membuka luasnya kemungkinankemungkinan di masa depan. Klien didorong untuk bebas bermimpi sebagai cara mengenali perubahan yang memang mereka inginkan. Pertanyaan ini memiliki focus masa depan yang 
dari situ klien bisa dapat memulai mempertimbangkan suatu jenis kehidupan yang berbeda yang tidak didominasi oleh suatu masalah tertentu.

Peserta didik perlu meningkatkan konsep diri akademik sejak dini dengan sering melakukan konsultasi dengan Guru Pembimbing sehingga dapat meningkatkan potensi yang dimiliki sesuai dengan kemampuannya. Khusus Guru BK/Konselor perlu meningkatkan kinerja dengan selalu mengupgrade diri melaui penelitian BK, serta memantaskan diri dengan selalu membantu siswa dalam meningkatkan konsep diri akademik dan tentu dengan menggunakan teknik-teknik yang tepat dan sesuai dengan permasalahan siswa.

\section{DAFTAR RUJUKAN}

Budiarsi, A.P, \&Zen, E.F.2016. Studi kasus konsep diri akademik siswa sekolah dasar. Jurnal kajian bimbingan dan konseling. Vol, no 3, hal. 112-117di kasus konsep diri

Hattie, J.2014. Self Concept. New York. Psychology Press.

Hurlock, Elizabeth B. 2003. Psikologi Perkembangan : Suatu Teknik Sepanjang Rentang

Kehidupan (Edisi Kelima). Terjemahan. Jakarta : Erlangga

Khafiya, Nida.H. 2018. Konsep Diri Akademik Pada Siswa MTS (Studi) Pada Siswa Yang berasal dari SD Umum. Fakultas Psikologi.Universitas Muhammadiyah Malang.

Mulawarman. 2014. Brief Counseling in Schools: a Solution-Focused Brief Counseling (SFBC) Approach for School Counselor in Indonesia. Journal of Education and Practice, 5(21) : 68-72.

Saifullah. 2015. Hubungan konsep diri akademik dengan prestasi akademik. Jurnal lisan. Volume 7, No.2.

Susanto, Hadi. 2016. Konsep Diri Akademis. https://bagawanabiyasa.wordpress.com/2016/08/24/ (Tanggal Akses: 13 September 2020) 